\title{
Mean Daily Variability of Energy Fluxes Above Alexandria Eastern Harbor
}

\author{
By Maged M.A. Hussein
}

\begin{abstract}
Mean daily variability of latent heat $(E)$, sensible heat $(H)$, net long wave $\left(L w_{n e t}\right)$, net short wave, and net flux of surface heat balance were estimated from hourly sea surface water temperature (SST) and meteorological time series obtained for three months during summer season (2019) in Alexandria Eastern Harbor (AEH), Egypt. Latent and sensible heat were not in phase and had their maximum 181.12 W/m $\mathrm{m}^{2}(5: 00 \mathrm{PM}), 16.5 \mathrm{~W} / \mathrm{m}^{2}$ (5:00 AM) and minimum 103.64 $\mathrm{W} / \mathrm{m}^{2}(8: 00 \mathrm{AM}),-12.14 \mathrm{~W} / \mathrm{m}^{2}$ (3:00 PM), resulting in Bowen ration of -0.11 and 0.09, respectively. The loss of heat by evaporation therefore predominates than sensible heat utilized to warm surface atmosphere. The instability of the atmosphere was existing nearly most of the time period, rising exchange coefficients of sensible and latent heat flux by about $24.26 \%$ over estimated neutral values (from $1.15 \times 10^{-3}$ to $1.43 \times 10^{-3}$ ). Mean Lw $w_{\text {net }}$ changed from 165.63 at early morning to $173.52 \mathrm{~W} / \mathrm{m}^{2}$ at late afternoon, point out its significant importance in the total balance of heat flux of eastern harbor surface. Latent heat flux and $L w_{\text {net }}$ were positive (energy losing from eastern harbor), throughout the day. The daily average of net energy budget $(S)$ was $38.52 \mathrm{~W} / \mathrm{m}^{2}$; daytime gain exceeded nighttime loss, with consequent heating the eastern harbor. Qualitatively, daily variations of net energy budget $(S)$ were nearly consistent with time delay to the variability of sea surface temperature, indicating the predominant role of the heat budget of the surface layer in modulating surface temperatures of the Eastern Harbor.
\end{abstract}

Keywords: heat flux, shortwave, long wave, latent heat, sensible heat, Eastern Harbor

\section{Introduction}

The main meteorological factors like the wind speed and forthcoming solar radiation contribute to the increasing of the mixed layer whilst water movement is the cause of temperature changes (hydrological processes) (Schertzer 1987). Energy fluxes across the surface of water body affect the water balance in addition to regulate or adjust heat storage (Hussein 2019). The conditions of atmospheric stability over the surface water can affect the heat fluxes of evaporative and convective from the surface water (Hussein 2019).

The heat fluxes (latent and sensible) represent the heat interchange between the atmosphere and ocean (Larid and Kristovich 2002). The heat budget of water body (lake, harbor, etc.) is controlled or governed by interaction with the above layer of the atmosphere. These interactions obviously are affected by the stability

\footnotetext{
"Professor, Laboratory of Physical Oceanography, Division of Marine Environment, National Institute of Oceanography and Fisheries (NIOF), Cairo, Egypt.
} 
of atmosphere over the surface water (Abbasi et al. 2017, Verburg and Antenucci 2010). The atmosphere over the surface water is unstable when the value of Obukhov stability length is non-positive (Abbasi et al. 2017, Verburg and Antenucci 2010, Brutsaert 1982). The air and water temperature (surface) differences can be utilized as an evidence of stability (Derecki 1981, Croley 1989, Verburg and Antenucci 2010). The loss of heat from surface water by the sensible and latent heat action is reduced when the atmosphere over it is stable and enhanced when the atmosphere over it is unstable (Brutsaert 1982). Unstable conditions of the atmosphere over water body can keep on long periods (Rouse et al. 2003). Lakes, harbors or any water body more extreme fluctuated from quite stable to quite unstable consequent to in general lower wind speeds and as well consequent to the maximal cooling and heating by the circumambient land (Abbasi et al. 2017).

The instability of the atmosphere above Alexandria Eastern Harbor occurred $96.09 \%$ of the time through the time period (6/6/2010 to 16/2/2011) and consequence in $24.55 \%$ rises in the evaporation in comparison to the neutral condition. The results denote that an unstable condition of the atmosphere has a significant or considerable impact in rising evaporation as well the flux of sensible heat (Hussein 2018).

The main objective of the present study was to collect and the necessary data to estimate the components of heat flux (latent, sensible, and long wave) and the net shortwave radiation and to determine the net surface heat flux balance. In this study, establish test the magnitude and relative role played by each flux component in the overall net surface heat balance and their average daily variability. Also, discuss the influence of the net heat flux on the observed daily variability of the surface layer temperature. Particular attention was given to the role of the atmospheric boundary layer (ABL) instability in strengthening the turbulent fluxes.

\section{Study Area}

Alexandria Eastern Harbor (AEH) (Figure 1) is a shallow, nearly enclosed and semicircular basin. It occupies nearly a central part of Alexandria coast with an area of about $2.80 \mathrm{~km}^{2}$. AEH is linked to the Mediterranean Sea via two outlets or openings: the main central outlet is called El-Boughaz and the second outlet is called El-Silsila. The slopes of the Harbor seabed gradually seawards, with an average depth of $5 \mathrm{~m}$ into the $\mathrm{AEH}$ and a reach to maximum depth of $13 \mathrm{~m}$ at the extreme eastern corner of El-Boughaz (Hussein and El-Geziry 2104, Hussein 2018, Hussein 2019). 
Figure 1. The Location of NIOF at Alexandria Eastern Harbour (AEH) Where the LTC Level Logger is Installed Since May 2019

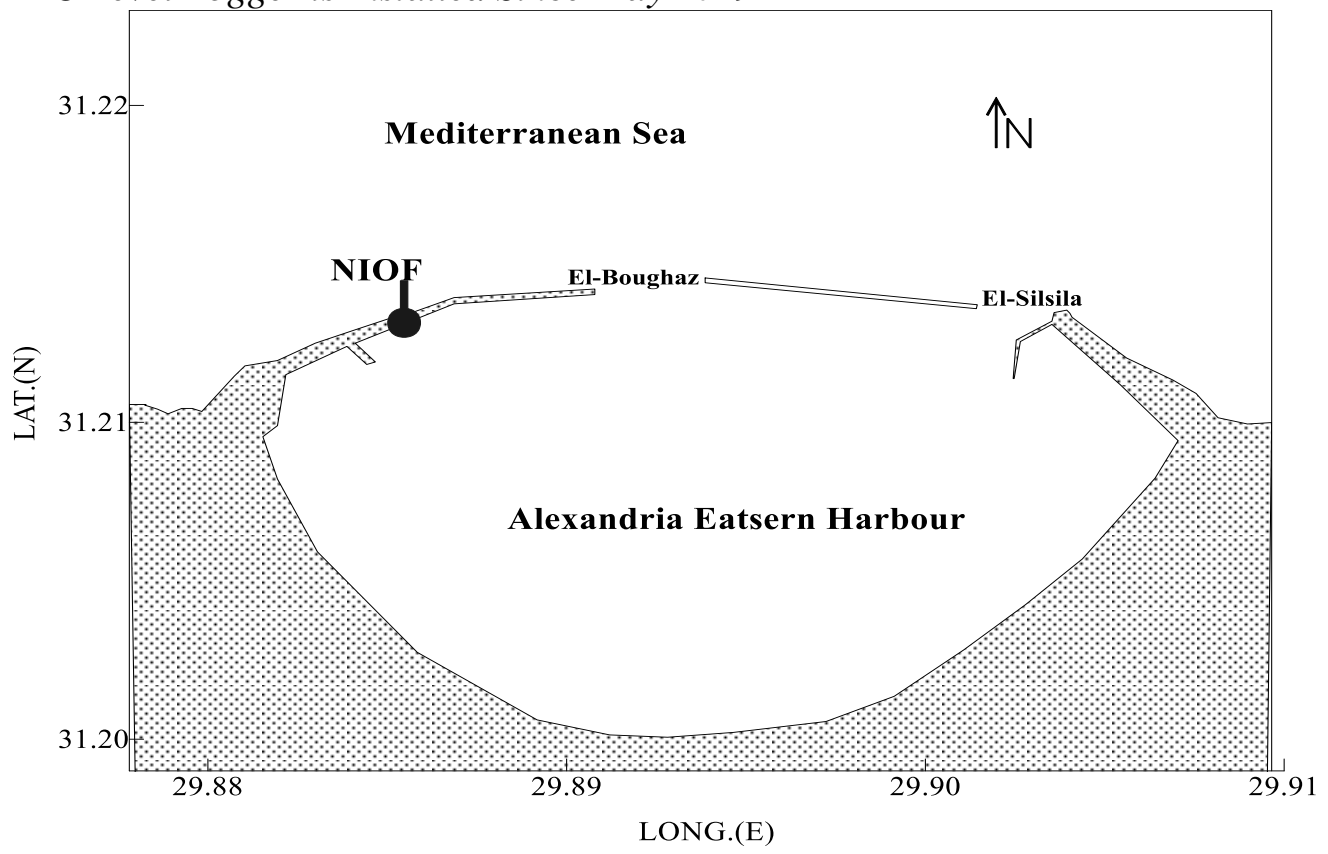

\section{Material and Methods}

Dataset

The hourly meteorological parameters measurements of AEH such as air temperature $\mathrm{T}_{\mathrm{a}}\left({ }^{\circ} \mathrm{C}\right)$, relative humidity $\mathrm{R}_{\mathrm{h}}(\%)$, wind speed $\mathrm{U}(\mathrm{m} / \mathrm{s})$, and atmospheric pressure $\mathrm{P}$ (hpa) were made for three months (92 days) began $1 / 6 / 2019$ and ended 31/8/2019 resulting in 2208 hourly data points per time series have been utilized to estimate the fluxes of latent and sensible heat of AEH. The Meteorological data has been supplied by the Alexandria Air Port meteorological station and acquired by means of the following website: https://www.wundergrou nd.com/history/daily/eg/alexandria/HEAX/date/2019-06-01.

Hourly sea surface temperature (SST) has been obtained from the device namely: (LTC - Level Logger), Temperature and Conductivity Logger immersed about $1.5 \mathrm{~m}$ under the water surface in $\mathrm{AEH}$.

\section{Methodology}

The fluxes of latent and sensible heat were calculated utilizing the Method of Bulk Aerodynamic, taking into consideration the dependence of the transfer coefficients on the stability of atmospheric boundary layer (ABL) (Amorocho and DeVries 1980, Imberger and Patterson 1990, Verburg and Antenucci 2010, Lorenzzetti et al. 2015). The fluxes of latent (E) and sensible heat $(\mathrm{H}) \mathrm{W} / \mathrm{m}^{2}$ were calculated from the following equations: 


$$
\begin{aligned}
& E=\rho_{a} L_{v} C_{e} U\left(q_{s}-q_{z}\right) \\
& H=\rho_{a} C_{a} C_{h} U\left(S S T-T_{a}\right)
\end{aligned}
$$

Where air density is $\rho_{\mathrm{a}}\left(\mathrm{kg} / \mathrm{m}^{3}\right)$, latent heat of vaporization is $\mathrm{L}_{\mathrm{v}}(\mathrm{J} / \mathrm{kg})$, specific heat of air is $\mathrm{C}_{\mathrm{a}}\left({ }^{\circ} \mathrm{C}\right)$, specific humidity at saturation pressure at SST is $\mathrm{q}_{\mathrm{s}}$ in $(\mathrm{kg} / \mathrm{kg})$, and specific humidity of air at height $\mathrm{Z}$ is $\mathrm{q}_{\mathrm{z}}(\mathrm{kg} / \mathrm{kg})$. The coefficients of exchange $C_{e}$ and $C_{h}$ are supposed to be equal (Zeng et al. 1998).

I have followed steps that have been used by Lorenzzetti et al. (2015) to calculate the following quantity: (1) Obukhov stability length L (m), (2) neutral transfer coefficients of atmospheric stability $\mathrm{C}_{\mathrm{dn}}, \mathrm{C}_{\mathrm{en}}$ and $\mathrm{C}_{\mathrm{hn}}$, that are utilize to obtain initial values for latent heat $\left(\mathrm{E}_{\mathrm{n}}\right)$, sensible heat $\left(\mathrm{H}_{\mathrm{n}}\right)$ and $\mathrm{u} *$ (friction velocity $\mathrm{m} / \mathrm{s}$ ), (3) functions of atmospheric stability $(\Psi)$, that depend on stability parameter $(\xi=\mathrm{Z} / \mathrm{L})$, (4) E, H, $\mathrm{C}_{\mathrm{e}}$ and $\mathrm{C}_{\mathrm{h}}$ were estimated after adjusted the coefficients, (5) net flux of long wave radiation $\left(\mathrm{LW}_{\text {net }} \mathrm{w} / \mathrm{m}^{2}\right)$ was calculated as the difference between the net incident $\left(\mathrm{Lw}_{\mathrm{inc}} \mathrm{w} / \mathrm{m}^{2}\right)$ and emitted $\left(\mathrm{Lw}_{\mathrm{emi}} \mathrm{W} / \mathrm{m}^{2}\right)$ long wave radiation, here cloud cover fraction supposed equal to 0 because there is seldom or no clouds in summer season in the study area. Also, I have followed method that has been used by Miyakoda and Rosati (1988) to estimate the values of short wave radiation.

\section{Results}

\section{Meteorology}

An evident signal was illustrated in the hourly values of relative humidity $\left(\mathrm{R}_{\mathrm{h}}\right)$, air temperature $\left(\mathrm{T}_{\mathrm{a}}\right)$ and wind speed $(\mathrm{U})$; sea surface water temperature (SST) likewise displayed a cycle pattern, but of quit smaller value than that for air (Figure 2). About $60.86 \%$ of the available data, the SST was greater than $T_{a}$, unstable condition of atmospheric boundary layer (ABL). Always in afternoon, air temperature $\left(\mathrm{T}_{\mathrm{a}}\right)$ was larger or warmer than SST in few degrees. In case of $\mathrm{T}_{\mathrm{a}}$ lower than SST during the day, it basically was enhancing the flux of sensible heat. Lower magnitudes of daily shortwave were happened directly after sunrise and before sunset. During afternoon, maximum radiation of shortwave varied between $837-1054 \mathrm{~W} / \mathrm{m}^{2}$. Relative humidity varied between $33-66 \%$ and wind speed hourly values varied between $1-8 \mathrm{~m} / \mathrm{s}$. 
Figure 2. Hourly Values of (a) SST at $1 \mathrm{~m}$ Below the Eastern Harbor Water Surface and Air Temperature $\left({ }^{\circ} \mathrm{C}\right),(b)$ Relative Humidity $(\%)$ and $(C)$ Wind Speed $(\mathrm{m} / \mathrm{s})$

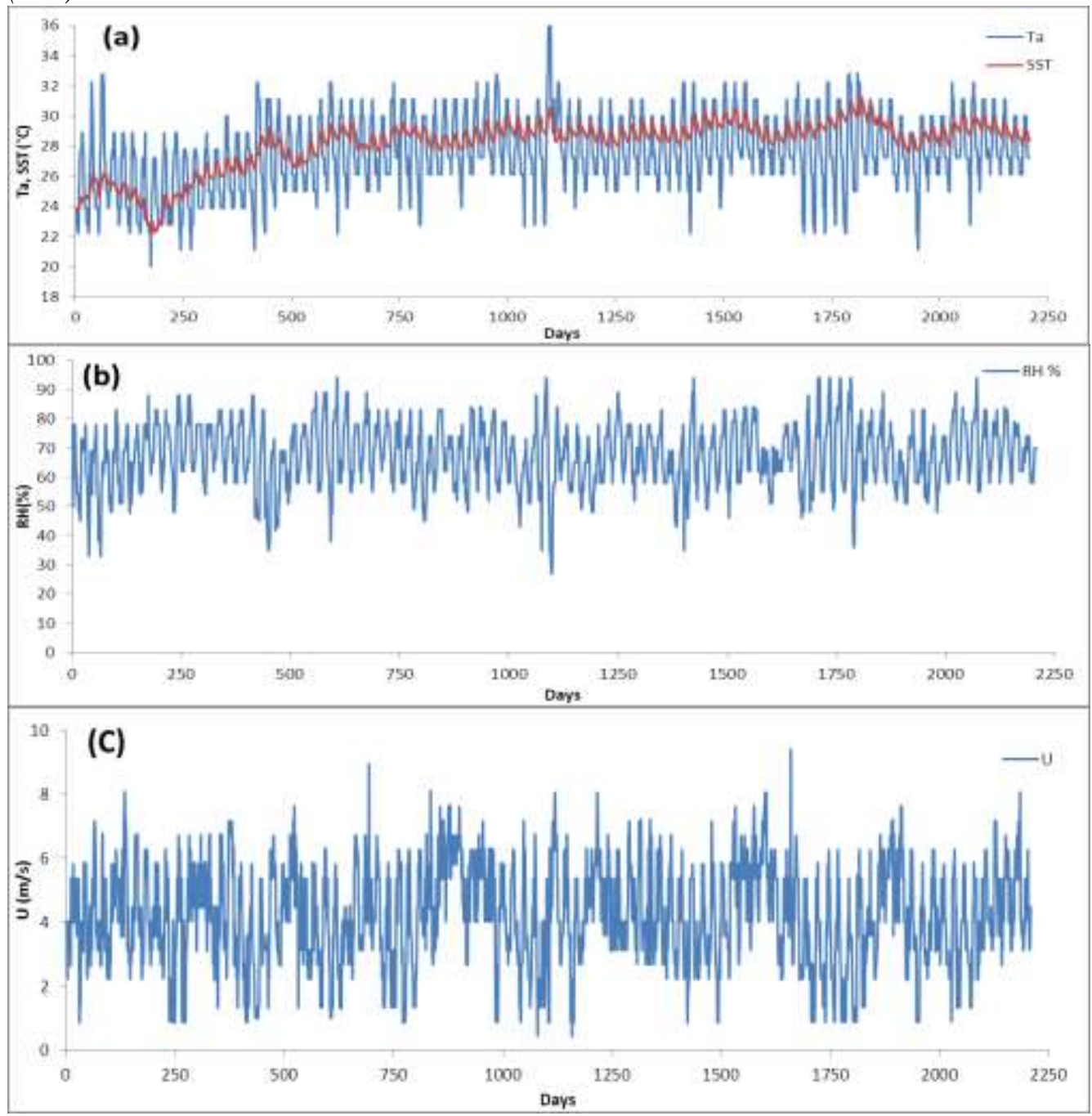

To calculate the daily cycle, each hour has been averaged of the 24 hours (day) utilizing the identical hourly magnitudes observed of the total period (Figure 3), which decreased the large frequency and the original weather data variability.

The mean daily of air temperature above the Eastern harbor displayed a temperature range of $5.68{ }^{\circ} \mathrm{C}$, with a minimum of $24.81{ }^{\circ} \mathrm{C}$ between $05: 00$ and 06:00 AM, after having declined from its maximum magnitude of $30.49{ }^{\circ} \mathrm{C}$ observed at 15:00 PM at midafternoon (Figure 3a). The temperature of surface water observed a weaker but identical behavior, lagging behind air temperature by about 1 hour, with a range of $4.77^{\circ} \mathrm{C}$ (Figure 3a). Air was colder than water after sunset until 8:00 AM; a little inversion was showed only at 15:00 PM, when $\mathrm{T}_{\mathrm{a}}$ was maximum and higher than SST by about $1.84{ }^{\circ} \mathrm{C}$. From 05:00 to 06:00 AM (end of the nighttime) air was colder than water at a maximum of $-2.91{ }^{\circ} \mathrm{C}$. This average cycle pattern of water and air temperature supports the scene presents in 
the actual or authentic data that the atmospheric boundary layer (ABL) over eastern harbor was unstable nearly most of the day.

Average wind speed $U$ was comparatively weak. There is no significant modification was viewed along the day. From about 6:00 to 7:00 AM, wind value was reach to its minimum of $3.09 \mathrm{~m} / \mathrm{s}$; from 9:00 AM to 16:00 PM it increase rapidly to a reach it is maximum of $5.71 \mathrm{~m} / \mathrm{s}$; and from 16:00 PM to 23:00 PM it decrease again to $3.64 \mathrm{~m} / \mathrm{s}$ (Figure $3 \mathrm{~b}$ ).

Maximum shortwave radiation (hourly mean) was about $1036 \mathrm{~W} / \mathrm{m}^{2}$, with sunrise about 00:06 AM and sunset at about 18:00 PM (Figure 3b). Figure 3C represents the difference of air and surface water temperature, SST was higher than $\mathrm{T}_{\mathrm{a}}$ from 19:00 PM to 9:00 $\mathrm{AM}$ and $\mathrm{T}_{\mathrm{a}}$ was higher than SST from 10:00 AM until 18:00 PM.

Figure 3. Mean Daily Variability of (a) SST and Air Temperature $\left(T_{a}\right)$, (b) Shortwave Radiation and Wind Speed and (c) Temperature Difference Between Water and Air Temperature

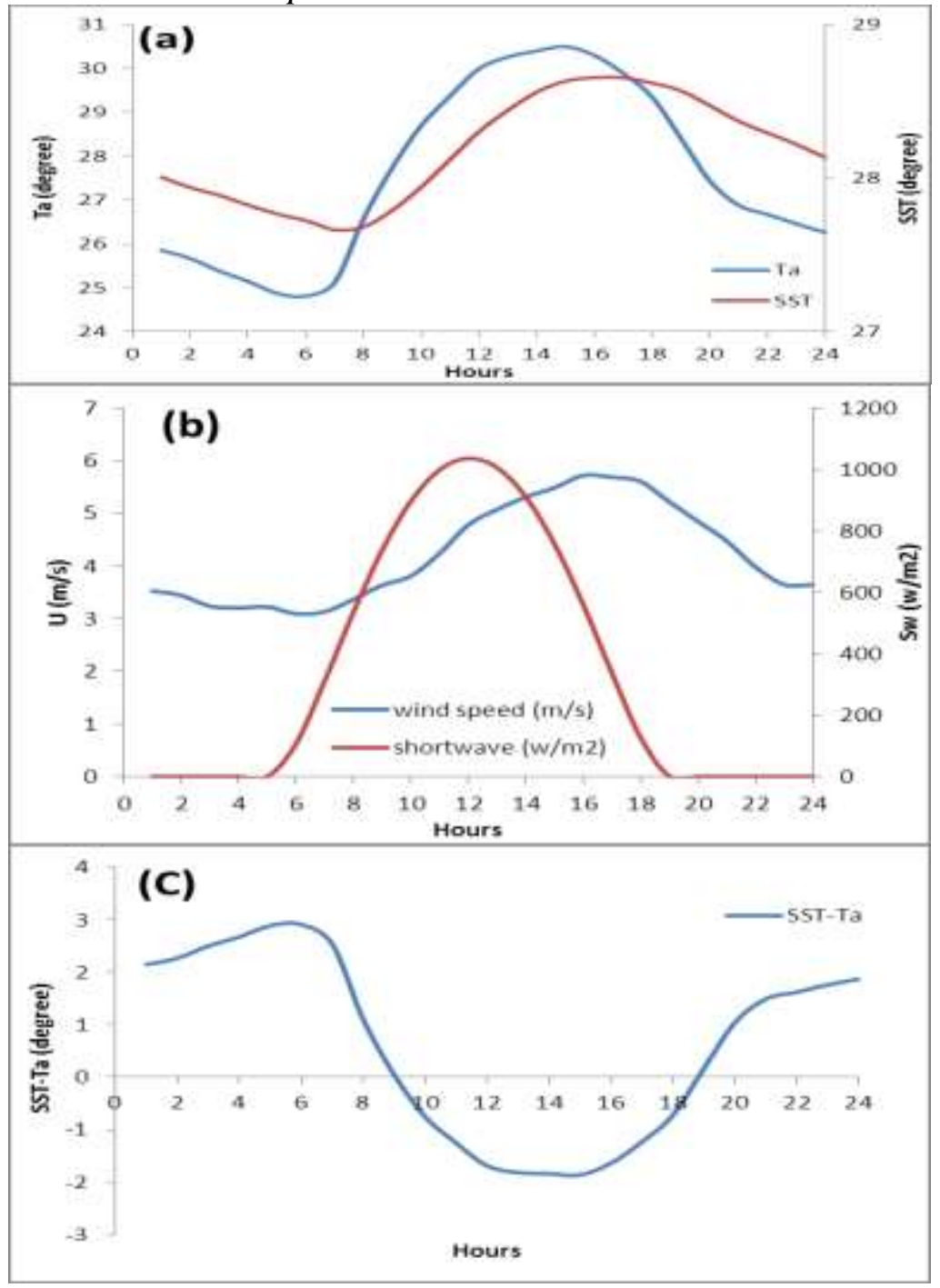




\section{Heat Fluxes of the Harbor Surface}

The hourly amounts of the heat loss from the surface for the entire observation interval (Figure 4) point to that the dominant component of the heat loss was net long wave, the flux of latent heat and flux of sensible heat (fluctuated between positive and negative values according to the temperature difference between SST and $\mathrm{T}_{\mathrm{a}}$ ). During the days, latent heat changed from 2.02 to 383.30 $\mathrm{W} / \mathrm{m}^{-2}, \mathrm{LW}_{\text {net }}$ from 138.30 to $197.90 \mathrm{~W} / \mathrm{m}^{2}$, and sensible heat from -49.23 to 40.00 $\mathrm{W} / \mathrm{m}^{2}$. During some hours of some days, latent heat loss was greater than net long wave radiation $(22.73 \%)$.

The maximum loss of total heat $\left(\mathrm{Lw}_{\text {net }}+\mathrm{E}+\mathrm{H}\right)$ during ordinary days was $582.05 \mathrm{~W} / \mathrm{m}^{2}$. The output results of big loss of heat was made by an increase in the latent and sensible heat fluxes created by high winds and a big SST-T temperature difference as shown in Figure 2. Table 1 represents the relationship between wind speed, SST-T $\mathrm{T}_{\mathrm{a}}$ temperature difference and the magnitude of latent heat, sensible heat and the total heat loss from the study area. From this table the maximum total heat loss $\left(\mathrm{Lw}_{\text {net }}+\mathrm{E}+\mathrm{H}\right)$ related to; high wind speed $8.05 \mathrm{~m} / \mathrm{s}$ (not associated with highest wind speed), almost low temperature difference $1.24{ }^{\circ} \mathrm{C}$ and moderate relative humidity $54 \%$. High total heat loss was $497 \mathrm{~W} / \mathrm{m}^{2}$ associated with highest wind speed $9.38 \mathrm{~m} / \mathrm{s}$, nearly low temperature difference $1.34{ }^{\circ} \mathrm{C}$ and relatively high relative humidity $70 \%$. The highest temperature difference $7.44{ }^{\circ} \mathrm{C}$, moderate wind speed $2.23 \mathrm{~m} / \mathrm{s}$ and high relative humidity $88 \%$ were produced the highest sensible heat $40.00 \mathrm{~W} / \mathrm{m}^{2}$, moderate latent heat $145.17 \mathrm{~W} / \mathrm{m}^{2}$ and relatively high total heat loss $377.57 \mathrm{~W} / \mathrm{m}^{2}$. Eastern harbor great flux appears related to a low sensible heat, created by a low SST-T $\mathrm{a}_{\mathrm{a}}$ temperature difference, and a larger latent heat related to high wind speed at the time of comparatively low relative humidity.

Figure 4. Hourly Values of Heat Losses from the Surface as Latent and Sensible Heat, Net Long Wave and Sum of All of Them

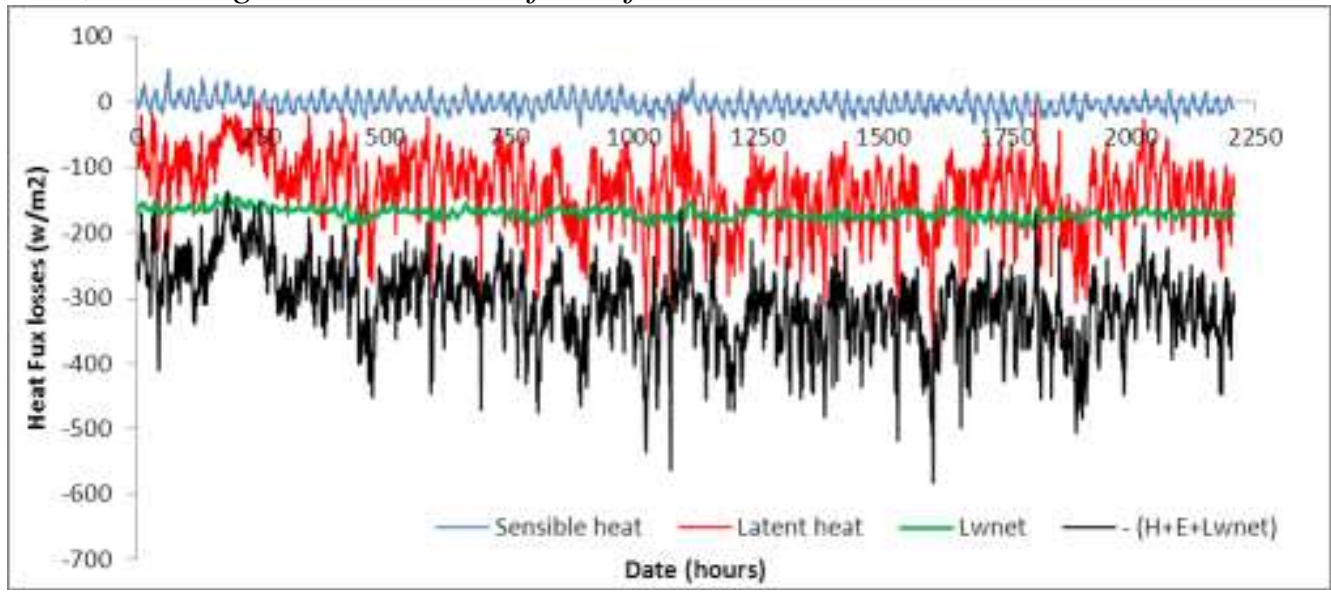

Table 1. Physical Parameters of Alexandria Eastern Harbor

\begin{tabular}{|c|c|c|c|c|c|c|c|c|}
\hline Humidity & SST & Ta & SST-Ta & Wind Speed & $\mathbf{H}$ & $\mathbf{E}$ & $\mathbf{L} \mathbf{w}_{\text {net }}$ & $\mathrm{H}+\mathrm{E}+\mathrm{L} w_{\text {net }}$ \\
\hline 54 & 29.01 & 27.78 & 1.24 & 8.05 & 15.89 & 383.30 & 182.86 & 582.06 \\
\hline 70 & 28.56 & 27.22 & 1.34 & 9.39 & 19.85 & 304.97 & 172.28 & 497.10 \\
\hline 88 & 29.67 & 22.22 & 7.45 & 2.24 & 40.01 & 145.18 & 192.39 & 377.58 \\
\hline
\end{tabular}




\section{Daily Variability}

Table 2 represents the major characteristics of the fluxes of latent and sensible heat and their input variables determined that the two most paramount components of the flux of latent heat are humidity deficit $\left(\mathrm{q}_{\mathrm{s}}-\mathrm{q}_{z}\right)$ and wind speed.

Mean daily magnitudes of relative humidity fluctuated between $55.82 \%$ (minimum) at 15:00 PM and 79.11\% (maximum) at 05:00 AM (Figure 5b) in inverse relationship to maximum and minimum temperatures of air, respectively (Figure 3a).

Vapor pressure saturation $\left(\mathrm{e}_{s}\right)$ at air temperature (Figure $5 \mathrm{~b}$ ) followed $\mathrm{T}_{\mathrm{a}}$, with a maximum at 15:00 $\mathrm{h}$, but vapor pressure $\left(\mathrm{e}_{\mathrm{a}}\right.$ ) (Figure 5a), was nearly minimum at this time, due to the relative humidity reduction. Vapor pressure saturation $\left(\mathrm{e}_{\mathrm{sat}}\right)$ at water temperature followed SST, with a maximum value at 17:00 $\mathrm{h}$ and minimum value at 07:00 h. Although $\mathrm{q}_{\mathrm{s}}$ and $\mathrm{q}_{\mathrm{z}}$ based on surface atmospheric pressure, their variability is almost equal to that of $\mathrm{e}_{\mathrm{sat}}$ and $\mathrm{e}_{\mathrm{a}}$ because the alteration in atmospheric pressure is only $1.38 \mathrm{hPa}(0.14 \%)$ during the day.

Table 2. Heat Fluxes (Hourly Mean) and Their Input Components

\begin{tabular}{|l|c|c|c|c|c|}
\hline & Max & Min & $\boldsymbol{\Delta}(\mathbf{\%})$ & Time Max & Time Min \\
\hline $\boldsymbol{\rho}_{\text {air }}\left(\mathbf{k g} / \mathbf{m}^{\mathbf{3}}\right)$ & 1.17 & 1.15 & 1.80 & $6: 00 \mathrm{AM}$ & $3: 00 \mathrm{PM}$ \\
\hline $\mathbf{1 0}^{-\mathbf{2}} \mathbf{L}_{\mathbf{v}}(\mathbf{J} / \mathbf{k g})$ & 24354 & 24330 & 0.09 & $7: 00 \mathrm{AM}$ & $4: 00 \mathrm{PM}$ \\
\hline $\mathbf{1 0}^{\mathbf{3}}\left(\mathbf{C}_{\mathbf{e}}=\mathbf{C}_{\mathbf{h}}\right)$ & 1.85 & 1.13 & 63.05 & $6: 00 \mathrm{AM}$ & $3: 00 \mathrm{PM}$ \\
\hline $\mathbf{U}(\mathbf{m} / \mathbf{s})$ & 5.72 & 3.09 & 84.77 & $4: 00 \mathrm{PM}$ & $6: 00 \mathrm{AM}$ \\
\hline $\mathbf{1 0}^{\mathbf{3}}\left(\mathbf{q}_{\mathbf{s}}-\mathbf{q}_{\mathbf{z}}\right)(\mathbf{k g} / \mathbf{k g})$ & 9.35 & 7.51 & 24.43 & $5: 00 \mathrm{PM}$ & $8: 00 \mathrm{AM}$ \\
\hline $\mathbf{S S T}-\mathbf{T}_{\mathbf{a}}\left({ }^{\circ} \mathbf{C}\right)$ & 2.91 & -1.86 & & $6: 00 \mathrm{AM}$ & $3: 00 \mathrm{PM}$ \\
\hline $\mathbf{E}\left(\mathbf{W} / \mathbf{m}^{2}\right)$ & 181.12 & 103.64 & 74.76 & $5: 00 \mathrm{PM}$ & $8: 00 \mathrm{AM}$ \\
\hline $\mathbf{H}\left(\mathbf{W} / \mathbf{m}^{\mathbf{2}}\right)$ & 16.5 & -12.14 & & $5: 00 \mathrm{AM}$ & $3: 00 \mathrm{PM}$ \\
\hline
\end{tabular}

Figure 5. Daily Variability of (a) Vapor Pressure $\left(e_{a}\right)$ at Air Temperature, and Saturation Vapor Pressure $\left(e_{\text {sat }}\right)$ at SST, (b) Saturation Vapor Pressure at Air Temperature, and Relative Humidity $\left(R_{h}\right)$

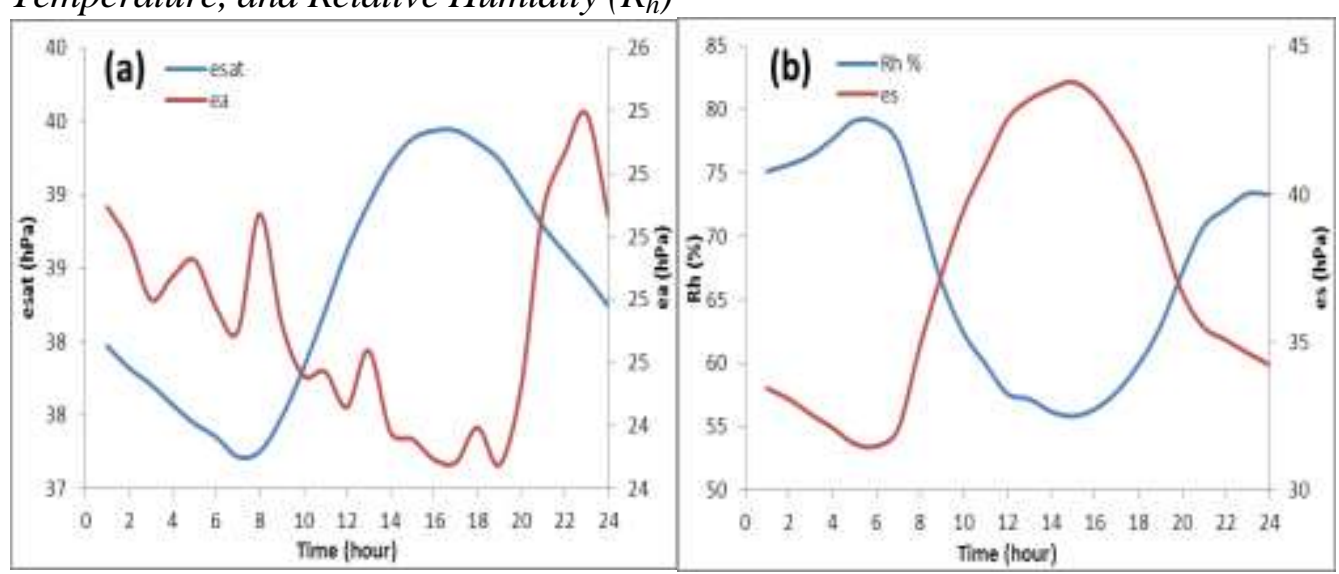

Figure $6 \mathrm{c}$ represents the mean daily variability of $\mathrm{q}_{\mathrm{s}}-\mathrm{q}_{\mathrm{z}}$. The maximum of humidity deficit occurred at 17:00 $\mathrm{h}$ (Table 2 ) because the minimum of $\mathrm{q}_{\mathrm{z}}$ is nearly 
simultaneous with the maximum of $\mathrm{q}_{\mathrm{s}}$ at this time during the day. So, the maximum humidity deficit $\mathrm{q}_{\mathrm{s}}-\mathrm{q}_{\mathrm{z}}$ is mightily predominated by the decrease in relative humidity linked to the air temperature peak.

Maximum value of latent heat $\left(181.12 \mathrm{~W} / \mathrm{m}^{2}\right)$ was observed at 05:00 PM (Figure 6a, Table 2), when surface wind speed reached $5.69 \mathrm{~m} / \mathrm{s}$ second highest value (Figure 3b). The decreases in latent heat between 01:00 AM and 08:00 AM and between 18:00 $\mathrm{h}$ to 23:00 $\mathrm{h}$ were quite determined by the decrease of the wind speed at these time intervals. Note that latent heat grew and fall during 24 hours also seems to be related with the $\mathrm{q}_{\mathrm{s}}-\mathrm{q}_{\mathrm{z}}$ behavior (Figure $6 \mathrm{c}$ ). The latent heat minimum value $\left(103.64 \mathrm{~W} / \mathrm{m}^{2}\right)$ was observed at 08:00 AM (Table 2), also $\mathrm{q}_{\mathrm{s}}-\mathrm{q}_{\mathrm{z}}$ was observed in minimum value at 08:00 AM (Table 2). This analysis represents that, while the wind speed controls latent heat and $\mathrm{q}_{\mathrm{s}}-\mathrm{q}_{\mathrm{z}}$, portion of the latent heat variability is still dominated by humidity deficit $\left(\mathrm{q}_{\mathrm{s}}-\mathrm{q}_{\mathrm{z}}\right)$.

Variability in latent heat of vaporization and air density (Figure 6b, 6d), which may be affect latent heat, were in phase with changes in sensible heat flux but not in phase with variations in flux of latent heat, their percent changes (Table 2) were very small to share in significantly to the latent heat variability.

The variability of the flux of sensible heat was not in phase with the flux of latent heat (Figure 6a). Note, that at 17:00 h, while maximum latent heat was $181.12 \mathrm{~W} / \mathrm{m}^{2}, \mathrm{H}$ was $\left(-8.20 \mathrm{~W} / \mathrm{m}^{2}\right)$, a result of a small SST-T $\mathrm{T}_{\mathrm{a}}$ temperature difference $-1.23{ }^{\circ} \mathrm{C}$ (Figure 6c) and a high wind speed $5.68 \mathrm{~m} / \mathrm{s}$ (Figure $3 \mathrm{~b}$ ) at this time of day. Sensible heat reached its maximum of $16.5 \mathrm{~W} / \mathrm{m}^{2}$ at 05:00 AM when SST $-\mathrm{T}_{\mathrm{a}}$ was maximum $\left(2.91{ }^{\circ} \mathrm{C}\right)$ and the wind speed was relatively low. In a mean daily sense, sensible heat flux was positive and negative during the day. On hourly basis (Figure 2) during afternoon and midafternoon hours, air temperatures can override SSTs, leading to negative flux of sensible heat (eastern harbor gaining or obtaining sensible heat). Sensible heat is a function of wind speed; winds are usually high during this time of the day. The average wind speed corresponding to these negative sensible heat fluxes was $5.07 \mathrm{~m} / \mathrm{s}$, resulting in high sensible heat flux gains in Eastern Harbor (average value of $-9.36 \mathrm{~W} / \mathrm{m}^{2}$ ). Also, take into account that during many hours sensible heat is positive (Eastern Harbor losing sensible heat) during the day. In an average sense, one can consider the values of sensible heat nearly positive (about $66 \%$ of the observation period) during the day. 
Figure 6. Daily Variability of Heat Fluxes (Sensible $(H)$ and Latent (E)), (b) Air Density $\left(\rho_{a}\right)$, (c) Temperature Difference Between SST-T and $q_{s} q_{z}$, (d) Transfer Coefficient of Mass and Heat $\left(C_{e n}\right.$ and $C_{h n}$ for Neutral Conditions)

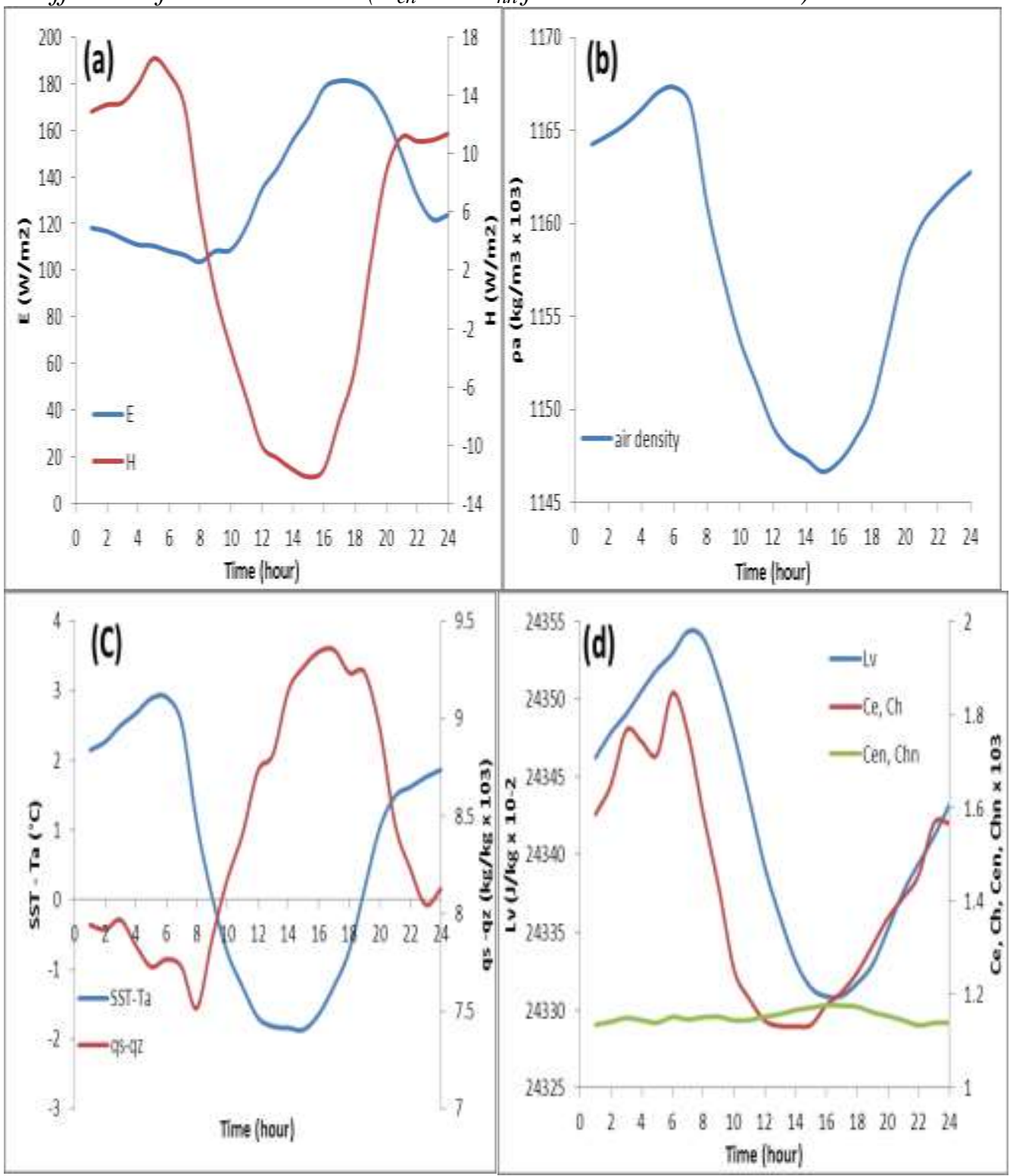

Fluxes of sensible and latent heat are influenced by variations in the exchange coefficients $\left(C_{h}\right.$ and $\left.C_{e}\right)$, that increment from their neutral magnitudes when the atmospheric boundary layer is unstable. In generic, cooler air above warmer water is related with unstable atmospheric conditions, nearly prevailing condition in Eastern Harbor. For humid and hot situations such as occur in summer season of the Eastern Harbor, atmosphere of Eastern Harbor can be unstable in that season, even when SST $-\mathrm{T}_{\mathrm{a}}=0$ (Hussein 2019) due to buoyancy has been induced by water vapor (Liu 1990). The parameter of stability $\zeta$ was nearly negative during $85 \%$ of the observation period. The estimated coefficients of heat transfer (Figure $6 \mathrm{~d})$ were nearly consistently over their neutral magnitudes, except from 12:00h to 
16:00h were slightly below their neutral magnitudes. $C_{e}$ and $C_{h}$, which were increase generally from midnight until 06:00 AM, then decrease rapidly until 011:00 AM and again increase from 16:00 h until nearly midnight, an increase associated with the decrease of the wind speed during this period (Figure 3b) accompanied by SST $-\mathrm{T}_{\mathrm{a}} \approx 1.31{ }^{\circ} \mathrm{C}$; a maximum negative $\zeta=-6.65$ was reached at this time. Between 16:00 $\mathrm{h}$ and 17:00 h, the atmospheric boundary layer was still unstable but at its minimum negative $\zeta \sim-0.032$ when the SST $-\mathrm{T}_{\mathrm{a}}$ is only $1.43{ }^{\circ} \mathrm{C}$ and wind speed is near its maximum; $\mathrm{C}_{\mathrm{e}}$ and $\mathrm{C}_{\mathrm{h}}$ were closest to their neutral conditions at this time of the day (Figure 6d). Even when SST and $\mathrm{T}_{\mathrm{a}}$ temperatures difference were close to $0{ }^{\circ} \mathrm{C}$ near 09:00 AM (Figure 6c), $\zeta \sim-1.74$, and $\mathrm{C}_{\mathrm{e}}$ and $\mathrm{C}_{\mathrm{h}}$ were well above $\mathrm{C}_{\mathrm{en}}$ and $\mathrm{C}_{\mathrm{hn}}$, the corresponding coefficients under neutral condition.

For the observation period, the average value of $\mathrm{C}_{\text {en }}$ was $1.15 \times 10^{-3}$. During the unstable conditions watched in Eastern Harbor, the average value of the heat transfer coefficients was $1.43 \times 10^{-3}$, a $24.26 \%$ increase above their neutral values.

Because the differences of pressure of water vapor $\left(\mathrm{e}_{\mathrm{sat}}-\mathrm{e}_{\mathrm{a}}\right)$ depend on $\mathrm{T}_{\mathrm{a}}, \mathrm{SST}$, $\mathrm{R}_{\mathrm{h}}$ and atmospheric pressure, and influence instability $(\zeta)$ and evaporation, they are beneficial or helpful for comparing buoyancy of water vapor and instability for various water bodies. For the study area $\mathrm{e}_{\mathrm{sat}}-\mathrm{e}_{\mathrm{a}}$ varied from 3.35 to $27.41 \mathrm{hPa}$ with a mean of $13.62 \mathrm{hPa}$. The similar (min, max, mean) $\mathrm{q}_{\mathrm{s}}-\mathrm{q}_{\mathrm{z}}$ magnitudes, were $2.06 \times$ $10^{-3}, 16.93 \times 10^{-3}$, and $8.40 \times 10^{-3}$ for Eastern Harbor, respectively. Consequently, in generic, the water vapor effects on latent heat and on atmospheric boundary layer instability in Eastern Harbor with about $3.35 \%$ and $27.41 \%$ greater for least and for extreme humidity deficits, respectively.

By linear regression fitting of latent heat $(\mathrm{E})$ versus $\mathrm{q}_{\mathrm{s}}-\mathrm{q}_{\mathrm{z}}$, wind and their multiplication, and sensible heat $(\mathrm{H})$ against SST-T $\mathrm{a}$, wind, and their multiplication, it is probable to get or gain additional quantitative account of the reliance of $\mathrm{E}$ and $\mathrm{H}$ fluxes to those variables. In Eastern Harbor, wind clarified $50 \%$ of latent heat variance, whilst humidity deficit clarified only $39 \%$, and their multiplication $88 \%$ (Table 3$)$. Note, the correlation between $U$ and $\mathrm{q}_{\mathrm{s}}-\mathrm{q}_{\mathrm{z}}$ in study area is very weak $\left(\mathrm{r}^{2}\right.$ $=0.0014)$.

For Eastern Harbor, whilst SST $-\mathrm{T}_{\mathrm{a}}$ has a predominant effect on sensible heat, the wind has moderate effect in modifying the sensible heat flux (Table 4). A weak correlation between wind and sensible heat was detected over the observation period $\left(r^{2}=0.24\right)$. At Eastern Harbor, diurnal variations of sensible heat were robustly bound to the changes in temperature differences $\left(S S T-\mathrm{T}_{\mathrm{a}}\right) ; \mathrm{r}^{2}=0.87$ (Table 4). For Eastern Harbor, the nearly perfect fit of latent heat versus the multiplication $\mathrm{U}\left(\mathrm{q}_{\mathrm{s}}-\mathrm{q}_{\mathrm{z}}\right) ; \mathrm{r}^{2}=0.88$ (Table 3) and sensible heat versus $\mathrm{U}\left(\mathrm{SST}-\mathrm{T}_{\mathrm{a}}\right) ; \mathrm{r}^{2}=0.93$ (Table 4) represents that latent and sensible heat can be precisely estimated via these linear relations with RMSE of about $19.14 \%, 3.1 \%$ of both latent and sensible heat, respectively.

Table 3. Correlation Between Latent Heat and Humidity Deficit and Wind Speed

\begin{tabular}{|l|c|c|c|c|}
\hline & & $\left(\mathbf{q}_{\mathbf{s}}-\mathbf{q}_{\mathbf{z}}\right)$ & $\mathbf{U}$ & $\mathbf{U}^{*}\left(\mathbf{q}_{\mathbf{s}}-\mathbf{q}_{\mathbf{z}}\right)$ \\
\hline $\mathbf{E}\left(\mathbf{W} / \mathbf{m}^{\mathbf{2}}\right)$ & $\mathrm{r}^{2}$ & 0.39 & 0.50 & 0.88 \\
\hline & RMS & 43.04 & 39.06 & 19.14 \\
\hline
\end{tabular}


Table 4. Correlation Between Sensible Heat and the Differences Between (SSTTa) and Wind Speed

\begin{tabular}{|l|c|c|c|c|}
\hline & & $\mathbf{U}$ & $\left(\mathbf{S S T}-\mathbf{T}_{\mathbf{a}}\right)$ & $\mathbf{U}^{*}\left(\mathbf{S S T}-\mathbf{T}_{\mathbf{a}}\right)$ \\
\hline $\mathbf{H}\left(\mathbf{W} / \mathbf{m}^{\mathbf{2}}\right)$ & $\mathrm{r}^{2}$ & 0.2 & 0.87 & 0.93 \\
\hline & $\mathrm{RMS}$ & 20.96 & 4.33 & 3.1 \\
\hline
\end{tabular}

An additional way of examining the relative impacts of humidity deficit, wind and air-SST differences on fluxes of latent $(\mathrm{E})$ and sensible $(\mathrm{H})$ heat is to assess the dependence of the variations of heat fluxes $(d E / E$ and $d H / H)$ on the fractional alteration of input variables, moisture difference at near surface $\Delta q(d \Delta q / \Delta q)$, wind $U z(d U z / U z)$ and air-SST $\Delta T(d \Delta T / \Delta T)$. The resulting in $d \Delta q / \Delta q=0.21, d U z / U z=$ 0.62 , and in case of $S S T>T a, d \Delta T / \Delta T=0.91$ and for SST $<\mathrm{Ta}, d \Delta T / \Delta T=0.79$. Thus, at eastern harbor variation in wind speed are more important than the changes of humidity deficit $\mathrm{q}_{\mathrm{s}}-\mathrm{q}_{\mathrm{z}}$ for the variability of latent heat (E) flux.

For the variability of sensible heat $(\mathrm{H})$ flux at Eastern harbor, the air-SST changes dominate rather than the wind (whether, Ta $>$ SST or Ta $\angle$ SST), in spite of the fact that wind changes are still important and significant.

For the summer season (observation period) at Eastern Harbor, the Bowen ratio changed from a minimum of -0.11 (sensible heat $=-12.14 \mathrm{~W} / \mathrm{m}^{2}$ at $3: 00 \mathrm{PM}$; latent heat $=103.64 \mathrm{~W} / \mathrm{m}^{2}$ at 8:00 $\mathrm{AM}$ ) to a maximum 0.09 (sensible heat $=16.5$ $\mathrm{W} / \mathrm{m}^{2}$ at $5: 00 \mathrm{AM}$; latent heat $=181.12 \mathrm{~W} / \mathrm{m}^{2}$ at 5:00 PM). This intrinsic variation in the Bowen ratio from minimum to maximum $(0.77$-fold) is moderate identified by an increase of sensible heat flux generated by the combined effect of slightly increases of wind speeds and maximum increase of SST- $\mathrm{T}_{\mathrm{a}}$ temperature differences during early morning time (5:00 AM), on other hand latent heat flux decreases at early morning.

The changes of sensible heat also point out that at night, and especially near sunrise, the influence of sensible heat on the Eastern Harbor atmospheric instability is quite higher. Note that there is no effect of atmospheric stability on Bowen ratio. Because the exchange coefficients $\left(\mathrm{C}_{\mathrm{e}}\right.$ and $\left.\mathrm{C}_{\mathrm{h}}\right)$ have been assumed to be equal, the modifications of these 2 coefficients created by variations of atmospheric boundary layer instability are equal, and then the ratio of sensible heat and latent heat is independent of the surface atmospheric instability.

Net flux of long wave $\left(\mathrm{Lw}_{\mathrm{emi}}-\mathrm{Lw}_{\mathrm{inc}}\right)$ hourly mean was positive (Eastern Harbor losing energy) during the day, changing from a minimum of $165.63 \mathrm{~W} / \mathrm{m}^{2}$ at 11:00 AM to a maximum of $173.52 \mathrm{~W} / \mathrm{m}^{2}$ at 06:00 $\mathrm{AM}$ (Figure 7a, Table 5). The fluxes of long wave (incident and emitted) were nearly in phase (Figure 7b), with their minimum and maximum at about 06:00-07:00 $\mathrm{h}$ and 15:00-16:00 h, respectively.

Due to the SST small period variability (Figure 3a), $\mathrm{Lw}_{\mathrm{emi}}$ represents only a small value of about $5.97 \mathrm{~W} / \mathrm{m}^{2}$ in contrast $\mathrm{Lw}_{\text {inc }}$ represents almost high change of about $12.25 \mathrm{~W} / \mathrm{m}^{2}$ (Table 5). The outcome was that the $\mathrm{Lw}_{\text {net }}$ maximum value was highly specified by the $\mathrm{Lw}_{\text {inc }}$ minimum value, which happens at 06:00 AM. 
Figure 7. Daily Variability of (a) Net Heat Flux of Long Wave (Lw net), (b) Emitted and Incident Long Wave, $L w_{\text {emit }}, L w_{\text {inc }}$ Respectively, and (c) Air Emissivity $\varepsilon_{a}$

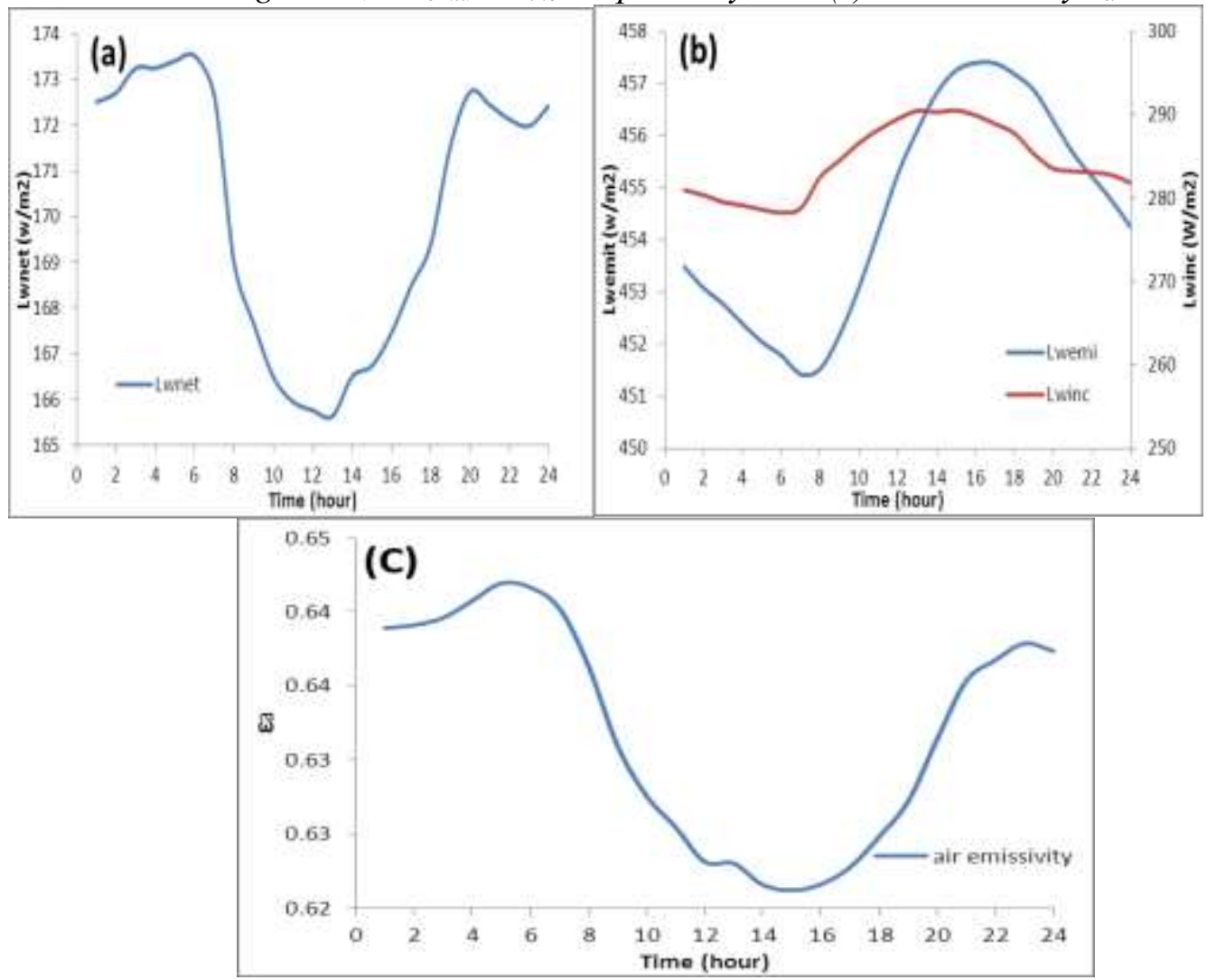

Table 5. Heat Fluxes of Incident, Emitted and Net Long Wave and Input Variables

\begin{tabular}{|l|c|c|r|c|c|}
\hline & Max & \multicolumn{1}{c|}{ Min } & \multicolumn{1}{c|}{$\boldsymbol{\Delta ( \% )}$} & Time Max & Time Min \\
\hline $\boldsymbol{\varepsilon}_{\mathbf{a}}$ & 0.642 & 0.621 & 3.3 & $15: 00$ & $05: 00$ \\
\hline $\mathbf{T}_{\mathbf{a}}$ & 30.495 & 24.813 & 22.9 & $15: 00$ & $06: 00$ \\
\hline SST & 28.654 & 27.665 & 3.5 & $16: 00$ & $07: 00$ \\
\hline $\mathbf{L w}_{\text {inc }}$ & 290.511 & 278.255 & 4.4 & $15: 00$ & $06: 00$ \\
\hline $\mathbf{L w}_{\text {emi }}$ & 457.395 & 451.418 & 1.3 & $16: 00$ & $07: 00$ \\
\hline $\mathbf{L w}_{\text {net }}$ & 173.523 & 165.639 & 4.8 & $16: 00$ & $06: 00$ \\
\hline
\end{tabular}

Air emissivity $\left(\varepsilon_{a}\right)$ (Figure 7c), which modifies $\mathrm{Lw}_{\text {inc }}$ (equation 5) depends nonlinearly on vapor pressure $\left(\mathrm{e}_{\mathrm{a}}\right)$ and depends inversely on air temperature (Figure 5a,\& 3a). By comparing the changes of $\varepsilon_{\mathrm{a}}$ (Table 5) and the incident flux of long wave, its secondary effect on $\mathrm{Lw}_{\text {inc }}$ is explicit.

The ratio of $\mathrm{Lw}_{\text {net }}$ to the fluxes of latent heat varied from $102 \%$ (at 17:00 h) to $164 \%$ (at 08:00 h), and the maximum net long wave was about 108\% greater than the max flux of sensible heat. These figures obviously display the importance of the $\mathrm{Lw}_{\text {net }}$ in the total heat flux balance of the surface (S).

The daily variability of mean balance of surface heat flux (S) for the observed period (Figure 8) represents that the average heat balance at the surface of Eastern Harbor was positive (warming) for about 10 hours around solar noon. The daily cooling period starts at 17:00 $\mathrm{h}$ and continue till early morning at $06: 00 \mathrm{~h}$; it is 
highly specified by the latent heat (evaporative losses). Before and after this phase, winds were nearly enough to promote the loss of latent heat to $107-181 \mathrm{~W} / \mathrm{m}^{2}$, making the magnitude of heat balance negative.

Figure 8. Surface Daily Variability of Fluxes of Heat Balance (S), Net Short Wave Flux $\left(E+H+L w_{\text {net }}\right)$, Short Wave Flux and Neutral Surface Heat Flux $\left(S_{n}\right)$

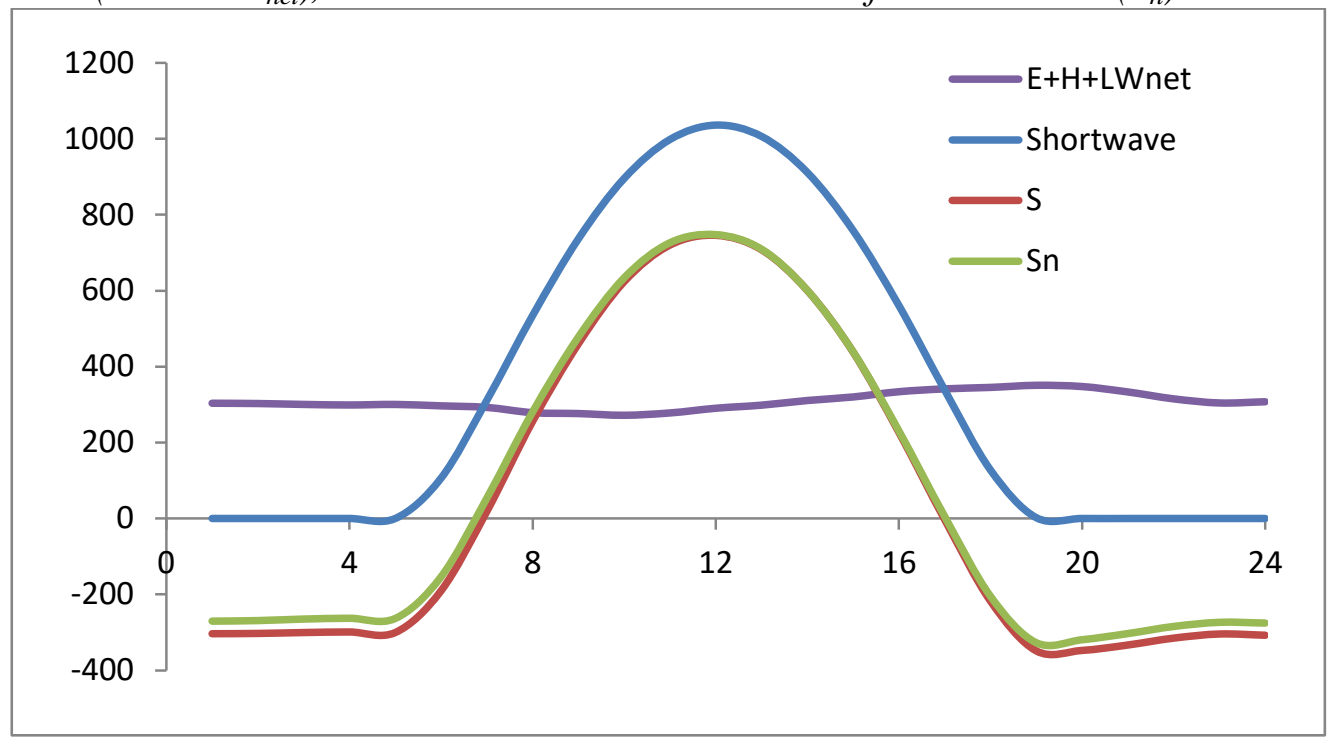

At Eastern Harbor, a daily average net heat flux of $38.52 \mathrm{~W} / \mathrm{m}^{2}$ was obtained by estimation of surface heat balance ( $S$ ) over the day. By using the conditions of neutral stability $\left(S_{n}\right.$ in Figure 8), drives to a daily average net heat flux of 59.67 $\mathrm{W} / \mathrm{m}^{2}$, an obvious indication of the important role of the atmospheric instability on the estimated fluxes of heat and net heat balance for Eastern Harbor.

Variations in SST are not only specified by the net heat flux of surface; also they depend on many others parameters (Kim 1976, Imberger 1985, Imberger and Patterson 1990, MacIntyre et al. 2002). If daily mean variability of SST is correlated with $\mathrm{S}$, however in principle, $\mathrm{S}$ should be the predominant factor. In comparing the daily variability of SST (Figure 3a) and S (Figure 8), SST started to grow at 08:00 AM, coinciding with the starting of a positive value (phase) of $\mathrm{S}$. The increase of SST stopped at 17:00 h when S turned into zero. From this time until 07:00-08:00 AM, when $S$ value was negative, SST decreased till its minimum magnitude at 07:00-8:00 AM. So, at least qualitatively, one can say that the observed variations of SST were governed by the net heat flux of the surface. The negative mean daily heat balance of surface through the period of the study indicates that energy is losing from Eastern Harbor.

\section{Conclusions}

Eastern harbor plays undoubtedly an important role as commercial environment for fishermen in addition to the uses of the eastern port in marine sports. 
The work explained in this manuscript was part of attempt and effort to combine and collect data in Eastern harbor and from it obtain a preferable description of each component of heat flux and the net heat flux of surface of AEH in a mean daily time frame. It particularly confirms understanding the relatively significance of each term or parameter of the budget of surface energy and how the value of each is governed by physical variables input during the daily cycle.

The latent heat (evaporative lose) was the predominant emission component of the heat flux (surface) at AEH. Higher latent heat value happens ordinarily at night when speed of wind is second highest value and minimum at morning when speed of wind is also second smallest value. During the observed time period, the mean latent heat was $141.38 \mathrm{~W} / \mathrm{m}^{2}$.

Wind over Eastern harbor was the main factor governing heat losses due to evaporation; the humidity deficit exclusively demonstrated about $39 \%$ of the variability of Latent heat $(\mathrm{E})$.

\section{References}

Abbasi A, Annor FO, van de Giesen N (2017) Effects of atmospheric stability conditions on heat fluxes from water surface in semi-arid regions. Hydrological Sciences Journal 62(9): 1422-1439.

Amorocho J, DeVries JJ (1980) A new evaluation of the wind stress coefficient over water surfaces. Journal of Geophysics Researches 85(C1): 433-442.

Brutsaert WH (1982) Evaporation into the atmosphere: theory, history, and applications. Edited by D Reidel. Dordrecht: Springer Netherlands.

Croley TE II (1989) Verifiable evaporation modeling on the Laurentian Great Lakes. Journal of Water Resource Research 25(5): 781-792.

Derecki JA (1981) Stability effects on Great Lakes evaporation. Journal of Great Lakes Research 7(4): 357-362.

Hussein MMA (2018) Evaluation of Alexandria eastern harbor evaporation estimate methods. Arabian Journal of Geosciences 11(24): 768.

Hussein MMA (2019) Impact of atmospheric stability conditions on heat fluxes from Alexandria Eastern Harbor, Egypt. Egyptian Journal of Aquatic Research 45(4): 313-319.

Hussein MMA, El-Geziry TM (2014) Diurnal variability of heat fluxes and Bowen Raito over Alexandria Eastern Harbor, Egypt. Journal of King Adul Aziz University: Marine Science 25(2): 57-85.

Imberger J (1985) The diurnal mixed layer. Limnology and Oceanography 30(4): 737770.

Imberger J, Patterson JC (1990) Physical limnology. In JW Hutchinson, TY Wu (eds.), Advances in Applied Mechanics 27, 303-475. San Diego (CA): Academic Press.

Kim JW (1976) A generalized bulk model of the oceanic mixed layer. Journal of Physical Oceanograaphy 6(5): 686-695.

Larid NF, Kristovich DAR (2002) Variations of sensible and latent heat fluxes from a Great Lakes Buoy and associated synoptic weather patterns. Journal of Hydrometeorology 3(1): 3-12.

Liu WT (1990) Remote sensing of surface turbulence heat flux. In GL Geernaert, WJ Plant (eds.), Surface Waves and Fluxes: Remote Sensing, volume II, 293-309. Dordrecht, The Netherlands: Kluwer Academic Publishers. 
Lorenzzetti JA, Araújo CAS, Curtarelli MP (2015) Mean diel variability of surface energy fluxes over Manso Reservoir. Inland Waters 5(2): 155-172.

MacIntyre S, Romero JR, Kling GW (2002) Spatial-temporal variability in surface layer deepening and lateral advection in an embayment of Lake Victoria, East Africa. Limnology and Oceanography 47(3): 656-671.

Miyakonda K, Rosati A (1988) A general circulation model for upper ocean simulation. Journal of Physical Oceanography 18(11): 1601-1626.

Rouse WR, Oswald CM, Binyamin J, Blanken PD, Schertzer WM, Spence C (2003) Interannual and seasonal variability of the surface energy balance and temperature of central Great Slave Lake. Journal of Hydrometeorology 4(4): 720-730.

Schertzer WM (1987). Heat balance and heat storage estimates for Lake Erie, 1967 to 1982. Journal of Great Lakes Research 13(4): 454-467.

Verburg P, Antenucci PJ (2010) Persistent unstable atmospheric boundary layer enhances sensible and latent heat loss in a tropical great lake: Lake Tanganyika. Journal of Geophysical Research 115(D11): 1-13.

Zeng X, Zhao M, Dickinson RE (1998) Inter comparison of bulk aerodynamic algorithms for the computation of sea surface fluxes using TOGA COARE and TAO data. Journal of Climate 11(10): 2628-2644. 